\title{
Em busca do tempo perdido: anotações sobre os determinantes políticos da crise do SUS
}

\author{
In search of lost time: notes on the political determinants of the SUS \\ crisis
}

Juarez Rocha Guimarães $\mathbf{1 , 2}$, Ronaldo Teodoro dos Santos ${ }^{\mathbf{2}, \mathbf{3}}$

DOI: 10.1590/0103-11042019S816

RESUMO Este artigo demonstra que há uma crise histórica dos sujeitos políticos que organizaram a dinâmica de fundação e construção dos Estados do Bem-Estar Social no pós-guerra, e que esta se manifesta na temporalidade própria e tardia da construção do Sistema Único de Saúde (SUS). O centro dessa crise estaria no processo de mudança epocal da tradição liberal, que passou a ter o paradigma neoliberal como dominante. A primeira parte do artigo apresenta os fundamentos políticos, a gênese e o desenvolvimento do pensamento neoliberal, localizando o seu ataque frontal às culturas da solidariedade, da fraternidade, do universalismo. O segundo momento do artigo demonstra como essa crise internacional afetou os sujeitos políticos fundadores do SUS, formando um contexto que, se não foi capaz de desconstitucionalizá-lo, minava suas bases financeiras e de legitimação pública. A terceira parte aponta que a repactuação histórica em torno do SUS passaria por uma (re)construção de seus sujeitos políticos em uma nova coalizão por meio do reencontro das culturas do republicanismo e do socialismo democráticos. Repondo a consciência sanitária neste novo horizonte civilizatório, renovando sua linguagem pública e sua capacidade de fazer convergir os novos movimentos sociais, o projeto SUS reataria o seu destino ao processo de refundação da democracia brasileira em crise.

PALAVRAS-CHAVE Reforma dos serviços de saúde. Sistema Único de Saúde. Sistemas políticos. Democracia.

1 Universidade Federal de Minas Gerais (UFMG), Departamento de Ciência Política (DCP) - Belo Horizonte (BH), Brasil.

2 Universidade Federal de Minas Gerais (UFMG), Centro de Estudos Republicanos Brasileiros (Cerbrás) - Belo Horizonte $(\mathrm{MG})$, Brasil.

3 Universidade do Estado do Rio de Janeiro (Uerj), Instituto de Medicina Social (IMS) - Rio de Janeiro (RJ), Brasil. ronaldosann@gmail.com

ABSTRACT This paper shows that there is a historical crisis of the political subjects that organized the foundation and construction dynamics of the Welfare States in the postwar period and that manifests itself in the late temporality of the construction of the SUS (Unified Health System). The crisis can be located in the change process of the liberal tradition, which came to have the neoliberal paradigm as dominant. The first part of the paper presents the political foundations, genesis, and development of the neoliberal thought, locating its frontal attack on the cultures of solidarity, fraternity, of universalism. Then, it shows how this international crisis affected the political subjects of the SUS, forming a context that, if not able to deconstitutionalize it, undermined its financial bases and its public legitimization. The third part points out that the historical renegotiation around the SUS would go through a (re)construction of its political subjects in a new coalition, through the reencounter of the cultures of democratic republicanism and socialism. Restoring sanitary awareness in this new civilizing horizon, renewing its public language and its ability to bring the new social movements together, the SUS project would reunite its destiny to the process of refounding the Brazilian democracy which is now in crisis.

KEYWORDS Health care reform. Unified Health System. Political systems. Democracy. 
Os impasses profundos vividos hoje na construção do Sistema Único de Saúde (SUS) não podem ser dissociados do fenômeno mais geral da crise das democracias - em particular, da democracia brasileira -, bem como dos impasses histórico estruturais das políticas de construção do Estado de Bem-Estar Social (Ebes). A narrativa histórica mais bem fundamentada do nascimento do SUS é aquela que o vincula à máxima afirmação dos direitos públicos do povo brasileiro, no momento decisivo de refundação da democracia. É essa grande narrativa histórica - que solda o destino do SUS ao destino da democracia - que precisa ser agora retomada.

A tese que iremos desenvolver neste artigo é que a temporalidade da fundação e da construção do SUS se insere nos grandes marcos de época da gradativa superação do liberalismo social ou keynesiano pelo neoliberalismo nas últimas quatro décadas. Essa dramática mudança no centro da tradição liberal, que organizava os fundamentos civilizatórios das democracias ocidentais no pós-guerra, foi vivida em uma temporalidade própria e em uma condição geopolítica particular, periférica ou semiperiférica, pela democracia brasileira a partir de sua refundação na Constituição de 1988.

A progressiva superação do liberalismo social ou keynesiano pelo neoliberalismo resultou em, pelo menos, quatro vetores de impedimento ou desestabilização do projeto de construção do SUS. Em primeiro lugar, foi-se implantando gradativamente um novo marco regulatório da macroeconomia, gerando fenômenos estruturais de ataque a arrecadação tributária, de desemprego estrutural e de precarização do trabalho, de endividamento público e restrições orçamentárias. Em segundo, incentivou-se um processo de deslegitimação das políticas universalistas e distributivas em prol de políticas focais e compensatórias. Em terceiro, levou-se a uma erosão dos valores da solidariedade, da igualdade e do pluralismo formando uma cultura de apartação social fortemente vincada aos valores mercantis, de legitimação das desigualdades e de culturas do ódio. Por fim, vieram se alterando os próprios procedimentos de funcionamento da democracia e da competição eleitoral que os vinculava ao princípio da soberania popular, em prol de uma autarquização do exercício do poder.

Esses novos condicionamentos políticos regressivos e adversos à construção do SUS devem ser entendidos em um contexto de época, em sua dinâmica internacional e em sua dinâmica de poder enquanto dominação. Trata-se certamente não de uma conjuntura, mas de uma acumulação de mudanças no tempo, que já se estende desde o começo dos anos 1980. Não se trata decididamente de um fenômeno nacional, mas geopolítico e internacional, no sentido que se refere a deslocamentos estruturais da correlação de forças em favor de poderes políticos econômicos que se expressam por meio da tradição política neoliberal. Enfim, o neoliberalismo veio se afirmando na medida em que promovia uma grave retração da democracia ao impor desregulação de mercados e dinâmicas autocráticas de exercício do poder.

Mais além disso, o deslocamento do liberalismo social ou keynesiano pelas correntes neoliberais tem provocado um impasse estratégico no horizonte das forças de esquerda, socialistas, eurocomunistas, trabalhistas ou social-democratas que se formaram ou se reorganizaram no ambiente da reconstrução liberal do pós-guerra. Em geral, as correntes neoliberais, na linha mesma do livro fundador dessa tradição, 'O caminho da Servidão', de Friedrich Hayek', estendiam uma política de 'guerra fria' não apenas aos comunistas, mas a todas às correntes que se inscreviam em uma linha democrática de construção da igualdade social. Isto é, o neoliberalismo provocou a ruptura dos pactos democráticos com eurocomunistas, trabalhistas e social-democratas, bem como com as formas institucionais e procedimentos de negociação das democracias liberais (formas corporativas tripartite, sistemas de coalizão parlamentar e de arbitragem judicial). Com esse movimento, 
corroía-se e deslegitimava-se a cultura de direitos que galvanizava as mais diversas forças políticas que entendiam a expansão social da democracia enquanto norteamento da história.

A partir desse diagnóstico político geral, que propõe pensar a Reforma Sanitária e os impasses do SUS como estreitamente ligados ao impasse da própria democracia em seu paradigma liberal social, este artigo percorre três etapas. Na primeira, buscamos identificar as linhas gerais do fenômeno político do neoliberalismo a partir da leitura de uma rica literatura internacional, ainda pouco difundida nas análises da saúde coletiva. Em seguida, considerando esse deslocamento mais amplo das tradições políticas que fundaram o EBES, segue a compreensão do rearranjo ideológico e programático dos partidos políticos e das múltiplas das forças sociais que contribuíram para os avanços da Reforma Sanitária e do SUS. Persegue-se, precisamente, os determinantes políticos adversos à construção do SUS resultantes do impacto do neoliberalismo sobre as forças políticas fundadoras da Reforma Sanitária. Por fim, esboçam-se, a partir do diagnóstico do impasse político do SUS, algumas diretrizes para a sua superação.

\section{Neoliberalismo e refundação do Estado democrático}

Apesar da forte influência da tradição neoliberal na vida política brasileira nas três últimas décadas, faz-se necessário aprofundar as reflexões sobre o alcance e implicações desse fenômeno sobre a construção democrática nacional. Estudos centrais sobre o assunto ${ }^{2,3}$ fornecem panoramas que permitem uma sistematização das diferenças de método e de leitura do neoliberalismo, a história de sua formação, interpretações de autores-chave e de correntes em seu desenvolvimento nos países capitalistas centrais. Além de mapas de think tanks e de influentes instituições internacionais, relações com grandes corporações financeiras e mesmo reflexões sobre a formação inicial de uma classe capitalista transnacional.

Em parte, a fraca entrada do neoliberalismo nas análises da ciência política, no estudo das políticas públicas e do próprio SUS se deve à abordagem economicista do conceito, amplamente predominante nos primeiros trabalhos, encerrando-o em um campo autônomo da crítica da economia política contemporânea, relacionando-o unilateralmente com os fenômenos da financeirização, globalização, pós-fordismo.

Por abarcar um conjunto de fenômenos coetâneos em escala internacional, por se referir a processos em curso de dimensão desigual perante diferentes tradições democráticas e, enfim, por abarcar pensamentos plurais no interior de um mesmo campo ou tradição política, o conceito de neoliberalismo ainda não se estabilizou ou está ainda sedimentando uma primeira referência comum.

$\mathrm{Na}$ construção desse entendimento, o caminho mais fecundo de teorização sobre o neoliberalismo tem-se revelado cada vez mais o da politização do conceito. Na linha das interpretações de Stuart Hall4, o neoliberalismo comparece como formador de uma nova hegemonia no campo liberal, como um novo regime de regulação do Estado, como desarticulador dos fundamentos da cultura e das instituições democráticas, como formador de novas relações de dominação promovidas organicamente por grandes corporações internacionais.

Um erro comum que vem senso superado é o de relacionar neoliberalismo, de forma unilateral, a um Estado fraco ou a um minimalismo da intervenção estatal. O que as correntes neoliberais propõem, em seu pluralismo, é uma forte mudança na cultura política e nos modos de regulação do Estado, a partir de um conceito de liberdade que se esteia em uma ontologia mercantil. O que a tradição neoliberal propõe é uma refundação do Estado liberal democrático, uma profunda reorganização de 
seu regime de regulação, uma positivação do conceito de liberdade em direção a seu sentido mercantil, em detrimento dos fundamentos da soberania popular e do universalismo de direitos. Gerardo Pisarello 5 propõe o tema da desconstitucionalização não democrática das democracias ocidentais, em graus diversos, nos anos recentes. O que resultaria não seria propriamente um Estado fraco, mas reforço e extensão qualitativa das suas dimensões coercitivas e funcionais à dinâmica mercantil em sua lógica financeirizada.

Embora Hayek ${ }^{\mathbf{1}}$ reclame para si a retomada dos valores e ideias políticas dos Old Whigs ingleses dos séculos XVII e XVIII, é mais preciso entendê-lo como um novo liberalismo. A sua obra propõe não apenas um limite ou redução da área de atuação do Estado (liberdade negativa) como faz o liberalismo clássico, mas também um acento ontológico na ordem mercantil espontânea como fundamento da liberdade, que deve ser garantida inclusive por um Estado forte (o liberalismo seria compatível com ditaduras) ou pela funcionalização de sua dinâmica e instituições à dinâmica mercantil, em que instituições e leis devem seguir a direção e o modus operandi do mercado.

Na década de 1960, Hayek ${ }^{6}$ propôs uma crítica geral aos direitos humanos: em sua formulação, a cultura dos direitos enfraquece a cultura da liberdade na medida em que impõe a terceiros o dever de tornar efetivo um direito afirmado a um. Há aqui uma oposição frontal entre liberdade e igualdade e uma negação do sentido público da formação da liberdade. Um ataque frontal às culturas da solidariedade, da fraternidade, do universalismo.

O livro de Mirowski e Plewhe7 é a principal obra de documentação da marcha histórica do neoliberalismo. Nessa trajetória, constam o Seminário Walter Lipmann no final dos anos 1930, a formação da sociedade Mont-Pelerin no pós-guerra, a Escola austríaca como ponto de encontro entre o ordoliberalismo alemão e a Escola de Chicago, a formação de redes internacionais vinculando grandes corporações e os think tanks, das décadas mais recentes. Essa documentação deveria ser completada com uma visão das três fases do neoliberalismo: disputa de agenda nos anos 1980, a partir das eleições de Reagan nos EUA e de Margareth Thatcher na Inglaterra; dissolução das identidades do liberalismo social, do trabalhismo e da social-democracia nos anos 1990; e um período pós-crise de 2008 , com a radicalização de programas de austeridade e de processos abertamente antidemocráticos.

Com esse movimento de desconstituição dos sentidos políticos que embasavam a face social das democracias liberais, chega-se à década da chamada Terceira Via de Blair e Clinton, das previsões de um 'fim da história' ante a estação liberal definitiva, nas quais seríamos todas e todos para sempre liberais, fixados ao triunfo do Ebes de tipo norte-americano. A política dos mercados financeiros ganhava novos direitos e novos interlocutores. É sob essa cosmologia política que os sujeitos políticos da fundação e da construção da Reforma Sanitária Brasileira foram desafiados a implementar o SUS.

$\mathrm{Na}$ literatura que estamos mobilizando, o campo neoliberal é visto como construção coletiva, que convive com um pluralismo de correntes, e que se adapta pragmaticamente a distintos contextos. Desde o final dos anos 1970, momento de nascimento da Reforma Sanitária Brasileira, assistimos a essa profunda mudança nos princípios civilizatórios dominantes, que, nas décadas seguintes, pôde ser sintetizada na supremacia orgânica e duradoura do neoliberalismo. Muitos livros recentes tratam do tema de como décadas de neoliberalismo produziram uma corrosão dos valores, das instituições e dos modos de sociabilidade próprios da democracia. O principal é 'Undoing the demos: neoliberalism stealth's Revolution', de Wendy Brown ${ }^{8}$. Nesse território desertificado e em crise de legitimidade da democracia, ocorrem fenômenos de crescimento de lideranças e forças políticas de ultradireita, de caráter fascista, com ampla audiência social. No centro dessa radical e dramática apartação entre os princípios da liberdade e da igualdade, cujo encontro, em 
diferentes linguagens políticas, formou a base política dos Ebes, encontram-se os fundamentos do neoliberalismo.

O movimento histórico de convencimento da razão neoliberal operou não apenas em uma frente macroeconômica e de redesenho do Estado social, como se inscreveu no âmbito dos valores sociais?. Desse modo, na entrada do século XXI, os marcos políticos de fundação do Ebes estavam em crise de identidade, desorientados programaticamente e em deslegitimação perante suas bases sociais e eleitorais. A tradição neoliberal, em suas várias vertentes, pôde então fazer a sua guerra de saturação: não mais pacto, mas denúncia, culturas do ódio e da execração; não mais Estado democrático liberal, mas um Estado autocrático vazado pela lógica da financeirização; não mais direitos, mas meritocracias da desigualdade. Enfim, o destino de aprender a ser livre em um mundo cada vez mais desigual.

O que havia de comum entre as três grandes tradições fundadoras do Ebes no pós-guerra era um horizonte marshalliano. Chamamos de horizonte marshalliano aquela imaginação política que encontrou uma bela síntese em 'Cidadania, status e classes sociais', de T. H. Marshall10, representando a tradição do liberalismo social fundada por John Stuart Mill. Por essa imaginação, a desigualdade estrutural de posicionamento das classes sociais iria se desvanecendo com a expansão e o aprofundamento dos direitos de cidadania na linha do tempo - direitos civis, direitos políticos, direitos sociais, depois, direitos da quarta geração, afirmava Bobbio"1.

A assunção do neoliberalismo veio exatamente minar esse chão e esse horizonte de expectativas nas mudanças incrementais, nos quais os sistemas universais de saúde foram tipicamente localizados. O 'ativismo institucional' a que se refere Gastão Wagner ${ }^{12}$ ao valorizar a militância dos diversos segmentos que combinaram resistência e realizações na construção do SUS evidencia um modo de caminhar e de fazer política em democracias que o neoliberalismo parece não mais transigir.
$\mathrm{Na}$ área da saúde, a superação desse fatalismo histórico a que a desrazão neoliberal precisa para se impor, exige, sem dúvida, uma atualização das perspectivas políticas sobre a condição de ser sanitarista no século XXI. Na linguagem da filosofia política, mais precisamente do humanismo cívico de Maquiavel e do republicanismo democrático, esse movimento de repactuação entre as exigências do tempo presente e as identidades matriciais se chama refundação. Refundar um Estado é retomar os valores da fundação em processo de corrupção, de desgaste e erosão, é atualizá-los diante de novas realidades.

Na próxima seção, o entendimento das linhas de força do neoliberalismo será complementado por um estudo específico dos modos e dinâmica de seu enraizamento no cenário pós-constituinte de 1988 no Brasil. Para tanto, serão consideradas as dimensões partidárias e institucionais, os deslocamentos da agenda política e o comportamento dos sujeitos diretamente responsáveis pela vitalidade da Reforma Sanitária Brasileira.

\section{Dos determinantes políticos da saúde na Reforma Sanitária Brasileira}

Os impasses duradouros do SUS devem ser entendidos como síntese histórica dos desafios políticos que se impuseram à coesão da sua base social de apoio. Em diálogo com o que foi discutido até aqui, apontaremos que a crise dos sujeitos políticos que fizeram a Reforma Sanitária e impulsionaram a construção do SUS está em compasso histórico com o ordenamento político neoliberal que atingiu as forças que sustentavam os Ebes, forjados no pós-guerra europeu.

Compreendida essa temporalidade de mutação das tradições políticas, nos lançamos à explicação da crise dos sujeitos da reforma sanitária procurando identificar de que modo suas conquistas históricas parciais 
conduziram seus fundamentos programáticos matriciais ao pragmatismo político-econômico das estruturas vigentes.

Em formulação gramsciana, essa mutação do programa sanitarista se refere ao complexo processo sociopolítico que modifica progressivamente a composição das forças sociais, arrefecendo suas identidades políticas e impedindo, com isso, que projetos transformadores avancem abertamente ${ }^{13}$. Remete-se antes à complexa dinâmica de desvirtuamento de princípios do que a interpretação conservadora da cooptação política, que reduz a relação entre líderes populares e o sistema político a interesses utilitários estreitos. Para além desse sentido fisiológico, trata-se de captar o movimento de crise dos sujeitos clássicos da Reforma, de sua coalizão; e, a partir daí, dizer dos seus desafios a uma repactuação e atualização histórica de seus fundamentos democrático-republicanos.

Na narrativa classicizada para explicar a origem da Reforma Sanitária, Escorel14 apontou a articulação de estudantes e médicos nos departamentos de medicina preventiva como detonadora de uma reviravolta que se daria na área da saúde, em fins dos anos 1970. Dessas instituições, surgiram importantes organismos do pensamento sanitarista, como o Centro Brasileiro de Estudos de Saúde (Cebes) e a Associação Brasileira de Saúde Coletiva (Abrasco). A experiência acumulada desses segmentos, articulada ao sindicalismo do setor, explicaria a difusão de projetos institucionais que abririam caminhos para a posterior sistematização do SUS.

Para além dessas narrativas, outro momento relevante é atribuído aos chamados 'reformistas da previdência'. Valorizando as disputas e decisões processadas no interior da burocracia do Instituto Nacional de Assistência Médica da Previdência Social (Inamps), essa vertente localiza o curso histórico da Reforma enfatizando estratégias de descentralização, como a criação do Sistema Unificado e Descentralizado de Saúde ${ }^{15}$. Aglutinam-se a essa explicação os gestores municipais, que, nos anos 1970, já se articulavam em oposição ao programa de saúde dos regimes militares com o movimento municipalista da saúde.

A contribuição dessas narrativas em destacar ângulos particulares e diferentes sujeitos da Reforma assume, no entanto, uma problemática convergência quanto à subvalorização da presença das camadas populares nessa trajetória. Gerschman ${ }^{16}$ documenta que os movimentos populares foram parte constitutiva dos rumos da Reforma, decisivos à formação e definição dos Conselhos Gestores como instâncias de caráter deliberativo da política de saúde, regulamentados, posteriormente, na Lei Orgânica da Saúde. O radical-popular, ao não abrir mão da sua presença nas transformações em curso, teria se configurado como a âncora de legitimação social das ações presentes em outros circuitos do movimento sanitarista.

Considerando as verdades parciais contidas nessas teses, é possível entender a centralidade pública que o tema da saúde alcançou para o entendimento pleno do que significava democratizar o País. A agregação das forças políticas que compuseram, articularam e, a seu modo, lutaram pela Reforma Sanitária e por um Estado democrático de Bem-Estar evidencia que sem uma ampla frente democrática dificilmente a saúde se tornaria um bem republicano a ser inscrito, pela primeira vez, como universal, público e gratuito, no coração do Estado brasileiro.

A predisposição à ação política das lideranças médico-sanitaristas presentes nas repartições públicas, desbloqueando decisões em espaços burocráticos fechados, o corpo a corpo da representação sanitarista no interior do sistema parlamentar, no momento constituinte, a radicalidade própria da soberania presente na ação popular e a formulação de um conhecimento engajado por parte dos departamentos de medicina social compõem, sem dúvida, as pontas do complexo movimento reformista. Complexidade esta que não se fez maior do que o entendimento consensual quanto ao interesse público articulado em torno da saúde. Essa força centrípeta forjaria o encontro da 
perspectiva político institucional, "consoante aos padrões políticos da tradicional esquerda comunista"17(96), com a militância de base da chamada 'nova esquerda', que, em torno do Partido dos Trabalhadores (PT), articulava amplos setores da esquerda católica e do expressivo Movimento Operário Popular em Saúde.

Como bem formulou Fleury ${ }^{18}$, a dinâmica histórica desse poder instituinte tornou-se condicionada aos rumos institucionais que foram definindo a política de saúde. Em diálogo com esse entendimento, destacamos que o esvaziamento dos sentidos políticos desse poder fundacional explica a crise de unidade dos seus sujeitos e seus limites em pautar a agenda pública da saúde. Para o desenvolvimento dessa hipótese, três fatos políticos que atuaram como vetores de força desagregadora nas décadas de implementação do SUS precisam ser delimitados: o Partido do Movimento Democrático Brasileiro (PMDB), desidratando seus segmentos da centro-esquerda e caminhando para a centro-direita; o Partido da Social Democracia Brasileiro (PSDB), caminhando da centro-esquerda para um ponto de vista programaticamente neoliberal; e o PT, desradicalizando o seu diálogo com o programa sanitarista rumo a um crescente pragmatismo em suas gestões.

Em primeiro lugar, nos anos 1990, a transição do liberalismo social presente na origem do PSDB à sua reafirmação neoliberal sedimentou-se institucionalmente em eixos que obstruiriam continuadamente a radicalidade original do programa reformista ${ }^{19,20}$ : i) na economia política, uma agenda de disciplina fiscal associada à abertura e desregulamentação progressivas dos mercados moldou o permanente subfinanciamento do SUS; ii) no âmbito institucional, um programa antiestado guiou reformas administrativas orientando parcerias com setor privado, e consolidou a competição regressiva do mercado da saúde com o SUS, via criação da Agência Nacional de Saúde Suplementar (ANS).

No segundo momento, que compreende os governos petistas, o aprofundamento de projetos caros ao campo sanitarista, sobretudo na atenção básica, não costurara a superação dos gargalos históricos que haviam sido pactuados na década anterior. Os momentos de adaptação pragmática àquele legado podem ser lidos como a desradicalização das forças sanitaristas que não conseguiram se impor como articulador político central de nenhum dos programas petistas de governo.

O terceiro fato político deve ser compreendido em sua transversalidade histórica, e se refere à perda da substância democrática reformista de importantes segmentos do PMDB, esvaziando de forma crítica a importância dos seus quadros forjados no liberalismo social. Desde a redemocratização, o PMDB se manteve como a legenda de maior bancada no Congresso Brasileiro. A aproximação de seus parlamentares com lideranças sanitaristas foi fundamental para o projeto SUS na Assembleia Constituinte, mas esse partido teve um curso para a centro-direita nos anos 1990, esvaziando seu sentido social e nacional-reformista. Como se encontra documentado, reuniões como a realizada em 1986 entre lideranças do campo sanitário, como Arouca e Eleutério Neto, e setores do PMDB, como Pedro Simon e Franco Montoro, evidenciam que estes "foram um importante aliado dos sanitaristas na luta pela democratização da saúde"21(241).

Nesses deslocamentos políticos, que inviabilizaram a permanência do modelo frentista de que se valeu a reforma sanitária, inscreve-se a fragmentação do campo sanitário na sua luta pela institucionalização do SUS, crescentemente disputado em várias frentes. Fixando-se mais como tradição constitucionalizada que como inteligência pública crescentemente organizada, a coalizão sanitarista sofreria com a resultante de forças que foi-se formando no pós-Constituinte. Assim, uma vez que a base política alcançada expressa limites para forjar a sua plena afirmação, passa a pressionar pela implementação parcial dos seus objetivos, acossado pelo deficit financeiro, pela pressão dissolvente privatista neoliberal e pelas dificuldades de gestão em um Estado não reformado democraticamente. 
Passadas as eleições de 1989, o sistema de representação parlamentar mostrava que a dinâmica do poder político se alterara em relação ao momento constituinte. À época, Arouca se elegia deputado federal pela primeira vez, pelo Partido Comunista Brasileiro (PCB), ao lado de mais dois correligionários, marcando a última representação da legenda no Congresso Nacional. Nas décadas seguintes, a contribuição do partido para conservar viva a inteligência e a tradição do projeto sanitarista original se manteria decisiva em núcleos da academia e da gestão pública, sem, contudo, possuir uma base política que lhe fosse orgânica.

No período democrático, o Congresso Nacional conservaria um perfil político predominantemente conservador, com forte poder de agenda e de veto. Em seu núcleo, a representação antissanitarista se articularia em torno das pautas do mercado da saúde e apoiaria sistematicamente transgressões no repasse de recursos ao SUS.

Por ocasião dos debates gerados em torno do financiamento, como a Contribuição Provisória Sobre Movimentação Financeira (CPMF) e a Emenda Constitucional (EC) 29, grandes esforços políticos articularam o Conselho Nacional de Saúde (CNS), os Conselhos Nacionais de
Secretários de Saúde (Conass) e das Secretarias Municipais de Saúde (Conasems), o Cebes e congressistas. Na campanha pela EC 29, o envolvimento do campo sindical e de atores novos, como o Movimento de Luta contra a Síndrome da Imunodeficiência Adquirida (Aids), foi notável. Em 2013, o Projeto 'Saúde +10', articulado pelo CNS, a Conferência Nacional dos Bispos do Brasil (CNBB) e mais de uma centena de entidades marcaram outro momento alto de articulação nacional em torno do SUS.

Esse panorama de lutas elucida que o financiamento se tornou o único tema capaz de alavancar unidade massiva dos setores sanitaristas no período democrático. Na condição de mobilizações sociais, propensas a se expressar em microconjunturas, a expressividade política alcançada não produziu fontes estáveis de custeio. Em 2000, com a aprovação da EC 29, o ganho histórico alcançado acumulou, todavia, deformações que decorreram da sua parcialidade ao vincular apenas a receita dos Estados e Municípios nos gastos da saúde. A pressão sobre esses orçamentos e o recuo no percentual dos gastos federais foram a tendência que se pode observar nos anos seguintes (quadro 1) ${ }^{\mathbf{2 2}}$.

Quadro 1. Gasto em saúde por ente federado, Brasil, 1990 a 2011 (\%)

\begin{tabular}{llll}
\hline Ano & Federal & Estadual & Municipal \\
\hline 1990 & $73 \%$ & $15 \%$ & $12 \%$ \\
2001 & $56 \%$ & $21 \%$ & $23 \%$ \\
2011 & $47 \%$ & $26 \%$ & $28 \%$ \\
\hline
\end{tabular}

Fonte: Piola et. al. ${ }^{22}$.

$\mathrm{Na}$ impossibilidade de alcançar soluções definitivas, as vitórias parciais incentivaram o pragmatismo crescente dos sujeitos da Reforma no âmbito da gestão do SUS. O PSDB, com seu projeto de SUS para os pobres, planos para os que podem pagar, aprovaria a chamada Lei de Responsabilidade Fiscal (LRF), em 2000, que, somada à reforma administrativa de Bresser-Pereira, em 1995, impactou as normas que operavam a gestão do SUS. Abrindo caminho ao pragmatismo dos contratos com as Organizações Sociais de 
Saúde (OSS), a terceirização e a precarização das condições de trabalho encamparam parcelas significativas da política de pessoal em vários níveis de assistência. Ao fixar o teto de despesas com pessoal na administração direta em $60 \%$, a LRF empurrou massivamente os gestores da saúde para uma realidade agressiva aos propósitos sanitários. Entre 2009 e 2016, considerando apenas o estado de São Paulo, as OSS aumentaram em $175 \%$ o seu gerenciamento nos estabelecimentos públicos de saúde, saltando de $22 \%$ para $58 \%^{23}$. Esse cenário apresenta o forte processo de assimilação política e diluição da crítica que os gestores sanitaristas nutriam ao chamado terceiro setor. Como destino manifesto, historicamente incontornável, qualquer força política do espectro partidário tornou-se permeável a essa realidade, presente, sobretudo, na administração dos municípios brasileiros.

Nesses 30 anos do SUS, gestores no Conass e Conasems foram fundamentais ao fortalecimento do sistema. Não obstante, como se assistiu em 2016, o persistente subfinanciamento federal e as externalidades da LRF subordinaram a longeva cooperação desses organismos ao cálculo econômico-corporativo. Do debate programático, fundado no interesse público, passou-se à desventura evasiva do realismo político, e estes gestores, imprescindíveis à reforma sanitária, apoiaram massivamente a contrarreforma aplicada à Atenção Básica, conduzida pelo governo que surgiu do golpe de $2016^{24}$.

Nos anos de governo do PT (2003-2015), esse cenário complexo de vetores da desagregação da frente democrática sanitária se reafirmou em momentos críticos. Importantes quadros dos departamentos de saúde coletiva ocuparam o Ministério da Saúde e suas repartições-chave, inclusive a ANS. Um inventário das possibilidades institucionais alcançadas pelo movimento da reforma nesse período revelaria, sem dúvida, o valor das políticas e programas formulados para os diferentes níveis de atenção. No entanto, as virtudes da ação política desses segmentos no âmbito da construção institucional encontram sua limitação central na incapacidade de se fazerem direção política ativa ao dissolver progressivamente seu diálogo com as frentes e movimentos populares. A tecnicização desses quadros soma-se à crescente profissionalização dos departamentos de saúde coletiva, que, como espaços de produção científica, também deslocaram, a seu modo, o papel político ocupado nas décadas anteriores ${ }^{25}$.

Nos anos 2000, quadros sanitaristas presentes na direção da ANS avançaram quanto ao direito dos consumidores e aperfeiçoamento de mecanismos de ressarcimento das operadoras ao SUS. Entretanto, acompanhando o movimento histórico de aterramento de princípios, observa-se nas pautas do CNS que essa oportunidade de pressionar o controle da assistência privada cedeu a um "notório desinteresse sobre os processos de regulação da saúde suplementar"26(290).

A ambivalência da ampliação de caminhos em meio à reposição crescente de obstáculos históricos ao sistema de saúde possui certo didatismo ao permitir considerações sobre como o esvaziamento do interesse público desarticula a identidade política de atores centrais da reforma. Como estamos identificando, esse movimento não consiste necessariamente no abandono consciente de bandeiras, mas na organicidade que o pragmatismo político assume sem que se perceba a perda na coerência do conjunto das lutas travadas.

Nos anos 1990, a consolidação mundial do neoliberalismo se fez sentir nacionalmente quando as orientações dos organismos internacionais passaram a ser repercutidas pelo próprio partido instalado no poder. O Banco Mundial, a Fundação Rockefeller e a Organização Mundial da Saúde (OMS) subsidiaram gabinetes estratégicos como o Instituto Casa das Garças, que passariam a formular diretrizes de agenda social em outra concepção de direitos. Diferentes concepções de universalidade, financiamento com fundos compartilhados guiados pela segmentação e seletividade estruturaram 
o que atualmente se chama Cobertura Universal de Saúde, em oposição aos sistemas universais de matriz social-democrata ${ }^{27}$.

Trabalhos recentes captam que corporações da medicina de mercado têm deslocado seu padrão de interação junto ao Estado por meio da colaboração com o setor privado ${ }^{28}$ e pelo processo de financeirização do mercado da saúde, cujos agentes têm poder de influenciar a dinâmica da política ${ }^{29}$. A autorização da participação e controle de empresas ou de capital estrangeiro na assistência à saúde, pela Lei ${ }^{\circ}$ 13.097/15, é exemplo desse processo.

É consonante com esse movimento histórico a demanda corporativa por seguros de saúde que amarra a representação sindical às expectativas da sua base social de apoio. O carecimento de uma consciência sanitária trabalhista, presente nos segmentos populares e de classe média, revela que essa cultura corporativa de direitos é um princípio político que desidrata estruturalmente a legitimação pública do SUS. Em 2017, 80\% dos seguros privados eram compostos por planos coletivos, formalizados com anuência sindical em convenções e acordos das categorias ${ }^{30}$. Os riscos de uma aproximação precária entre sindicalistas e sanitarista haviam sido identificados por Belinguer, nos anos 1970. Em que pese a profundidade histórica da questão, teses relevantes do campo sanitarista têm, predominantemente, atribuído a expansão desses seguros à vontade patronal, ou aos incentivos realizados pelo Estado ${ }^{31}$.

No processo de implementação do SUS, a vigilância em saúde do trabalhador e os centros estaduais e municipais de saúde do trabalhador configuraram novidades históricas fundamentais. O seu alcance parcial, no entanto, pode ser percebido pelo próprio envolvimento sindical com o mercado da saúde.

Nas últimas três décadas, a participação e o controle social mudaram de patamar histórico. Formalmente, os conselhos de saúde estão em todo o País. A mobilização de movimentos organizados da saúde e usuários apresentou uma dinâmica política de fiscalização que superou a crítica de que os conselhos seriam apenas foros de cooptação de energias políticas transformadoras.

Considerando a importância das conferências e conselhos presente nos vários momentos analisados nesta seção, é importante dizer que essas instâncias não ficaram imunes ao movimento de desagregação dos sujeitos clássicos da Reforma. Sob a inflexão neoliberal de asfixiamento financeiro do sistema, de legitimação das várias frentes regressivas do interesse privado na gestão pública, e amparo aos deslocamentos ideológico-programático das coalizões governativas desse período, os movimentos populares arrefeceram sua capacidade de pautar alterações constitucionais contundentes - como aquela alcançada pela introdução da participação social na lei orgânica da saúde, em 1990.

Como procuramos analisar, nos últimos 30 anos, as forças sanitaristas travaram uma luta em plena retaguarda, resistindo e se ajustando ao novo marco político que regulava as atuações do campo. Aos ganhos da constitucionalização incremental da assistência, enredados em momentos pontuais de campanhas nacionais pelo financiamento do SUS, seguiu-se a assimilação política aos obstáculos mais estruturais impostos por uma razão neoliberal que sufocava a própria força da democracia. Considerando essa ambiência, é possível dizer que a coalizão sanitarista se fixou mais como tradição constitucionalizada que como inteligência enraizada nos valores públicos que compõem a cidadania política de milhões de brasileiros.

\section{Por um tempo Sergio Arouca de refundação do SUS}

Se bem fundado o plano histórico internacional de análise do impasse do projeto SUS - a crise epocal de seus sujeitos históricos de fundação -, seria necessário reconhecer, em primeiro lugar, a temporalidade própria do poder instituinte e institucionalização do SUS, 
seguindo sempre as pistas do pensamento de Sonia Fleury ${ }^{18}$. Se a instituição do SUS foi um dos últimos capítulos de uma era do Bem-Estar social, sua institucionalização já se deu na era de ascensão do neoliberalismo como corrente dominante na tradição liberal. Pensado assim, o tempo da fundação nunca deixou mesmo de se contrapor ao tempo da institucionalização, como se a memória da origem e o plano de um futuro pleno do SUS tivesse se engarrafado na 'profusão das coisas acontecidas' de um tempo adverso.

Era inevitável, nesse contexto, que à figura do sanitarista fundador e programático se contrapusesse, em tensão, a figura do sanitarista pragmático e construtor. Seria necessário, nesse sentido, promover o reencontro entre esses sujeitos, somando ao finalismo heroico do primeiro o sentido de realidade - a força das coisas - do segundo.

A tentação do prefixo neo, nomeador desse novo sujeito sanitarista, deveria ser inscrita na própria figura dessa bela tradição, ciosa de formar o elo entre as gerações. Seria equívoco opor o novo ao velho, em uma história que vai apagando seus rastros em busca sempre de um ponto zero, um começo fora do tempo, como se em uma sociedade brasileira, cujas linhas de continuidade são tão profundas e retesadas, o novo pudesse se erigir sem prestar contas ao passado. O que se requer não é propriamente a negação do passado, mas a consciência crítica de sua tradição, que nunca pode deixar de ser, ao mesmo tempo, uma atualização de perspectivas. Para quem se inscreve em uma tradição, o tempo não é propriamente um inimigo que se deve expulsar da própria casa, mas um companheiro de viagem ao qual devemos sempre a angústia do sentido. Em síntese, o que se precisa é um novo tempo Arouca do SUS no século XXI, uma refundação para o Estado de Bem-Estar brasileiro.

Chamar este tempo de refundação de Sergio Arouca é mais do que prestar homenagem à consciência das determinações sociais da saúde. Essas determinações sociais são, por sua vez, fundamentalmente condicionadas pela política. O tempo de refundação Sergio Arouca do SUS deve ter como consciência a transformação das determinações políticas da saúde.

A ciência política cada vez mais está desafiada a compreender a democracia, não ao modo minimalista e procedimental do liberalismo, mas como forma de organizar a vida social em um princípio civilizatório de liberdade, igualdade e fraternidade. A saúde, bem público fundamental, está inevitavelmente associada ao destino de nossas democracias: à oferta dos alimentos, dos cuidados, dos modos de trabalhar e de descansar; à liberdade sexual e ao sentidos comunitários e afetivos de viver junto; aos modos de viver a infância, a adolescência e o envelhecer; às relações entre os gêneros e as diversidades étnicas; às geografias das cidades; aos modos de se integrar ou predar a natureza. A democracia, entendida em sua raiz republicana, é a forma livre de viver bem em saúde e em comum.

Ora, a época do neoliberalismo é, por excelência, a época de predação da democracia e, por consequência, do princípio público da vida. De Polanyi32 a Achile Mbembe ${ }^{33}$, em seu belo 'Crítica à razão negra', a consciência radical e crítica dos tempos do neoliberalismo é cada vez mais ciosa em captar a generalização de suas pulsões de morte. E não há nada mais mortal - a consciência sanitarista sabe mais disso do que ninguém - do que submeter as políticas de saúde ao princípio da valorização mercantil.

A forma política histórica da tradição do liberalismo social foi, em seu centro, o mix público-privado. No entanto, esse hibridismo, formado em um tempo de equilíbrio de forças do pós-guerra, rompeu-se definitivamente com a ascensão do neoliberalismo para a funcionalização cada vez mais evidente do que é público pela dinâmica em expansão das formas do privatismo mercantil. Se em sua primeira fase o neoliberalismo quis redefinir os limites do público, por meio das agendas do Estado mínimo, na segunda, guiado pela chamada Terceira Via, ele pretendeu funcionalizar o público ao privado. Nesta terceira fase, pós-crise internacional de 2008, ele quer mais 
propriamente destruir o que é público e até redesenhar o sistema político não mais pela soberania popular, mesmo que rala, mas pela soberania dos endinheirados.

As tradições do chamado 'socialismo liberal'11 que historicamente fizeram um mix entre o princípio da liberdade liberal e o princípio da justiça contido nas tradições socialistas são, pela sua própria gênese, incapazes de fazer frente à época do neoliberalismo; pois o que o neoliberalismo investiu foi exatamente na própria redefinição do que é entendido como liberdade no interior da tradição liberal, ressignificando-a não mais como um princípio negativo de contenção do Estado, como queria o liberalismo clássico, mas como princípio positivo em que a esfera estatal impõe com pujança a ordem mercantil.

As melhores tradições da transformação do mundo sempre procuraram compatibilizar o diagnóstico crítico dos tempos com a coerência dos caminhos de superação de suas opressões. Mais do que nunca, é preciso, então, sintonizar diagnóstico e programa.

A crise dos sujeitos históricos de fundação do Welfare State e do próprio SUS, assolados pelo neoliberalismo, só pode ser superada com a refundação política de seus sujeitos históricos de construção no século XXI. Somente as tradições de um socialismo democrático, que reclamam para si as tradições do republicanismo democrático e as atualizam, pode estabelecer com coerência uma narrativa de refundação e uma nova era dos direitos.

O que caracteriza centralmente essas tradições clássicas e contemporâneas do socialismo democrático é a não separação do princípio da liberdade e de igualdade. Não se pode ser livre em um mundo de desiguais e muito menos se pode aspirar a ser igual em um mundo sem liberdade. A forma política, por excelência, das tradições do socialismo democrático nessa perspectiva é exatamente o que é público em oposição ao privatismo mercantil. Os valores, os sentimentos, as identidades e o programa do que é comum - esta compreensão que a liberdade subjetiva mais rica reivindica a intersubjetividade entre pessoas de igual dignidade mesmo em sua diferença - devem prevalecer na democracia.

O SUS é, sobretudo, a experiência mais ousada do que é público e do que é comum na experiência democrática brasileira do pós-1988. Em uma tradição desde sempre marcada pela formação corporativa dos direitos, profundamente desarticulada e desigual em seus tempos, esse comum lugar constitui um topos, um radical muito elevado, que só pode mesmo se formar no próprio processo de refundação da democracia brasileira. O SUS, talvez em sintonia mesmo com o samba, a mais universal de todas as nossas instituições, só pode ser na democracia.

Pensar, então, a formação dos novos sujeitos de construção do SUS no século XXI é imaginar a formação de uma ampla frente democrática, com os socialistas democráticos em seu centro, e programatizada para acolher a imensa variedade dos sujeitos que querem 'Bem-Viver' e em saúde.

A vida é a arte do encontro, já nos disse o poeta, embora haja tanto desencontro na vida. O SUS precisa agora de um grande reencontro, misturar os seus sonhos com as utopias das novas gerações de movimentos feministas, negros, LGBTIs, quilombolas e povos indígenas, que procuram construir a dignidade de seus direitos e de seus modos de viver.

A este encontro, não podem faltar as classes trabalhadoras. Nestes tempos nos quais se programatiza a precarização da própria dignidade do trabalho, o SUS deve ser também a casa comum dos trabalhadores, cada vez mais frustrados com a medicina mercantilizada e as carências dos seguros de saúde privados. Para uma tradição socialista democrática, seria um grande erro histórico separar as aventuras identitárias da clássica centralidade dos direitos de quem vive do trabalho.

A construção histórica desses novos sujeitos refundadores do SUS, como parte de uma frente democrática mais ampla, capaz de atrair para si todos os setores progressistas e de centro-esquerda, permitiria tratar os 
impasses históricos de construção do SUS - o financeiro, o mercantil, o de gestão - em um novo enquadramento político republicano democrático, isto é, com o princípio do que é democrático e público no comando.

O que é necessário deve se tornar possível. Exceto em alguns momentos conjunturais nos quais o tema da corrupção aparece excepcionalmente como prioridade, o direito à saúde frequenta, há vários anos, o primeiro lugar na agenda das reivindicações dos brasileiros. Há, pois, um fosso entre a legitimidade e o processo de legitimação do SUS. A construção desses novos sujeitos refundadores do SUS no século XXI seria, nesse sentido, um caminho possível de aproximar e até fundir a legitimação do projeto SUS ao sonho comum dos brasileiros e brasileiras de viver bem e em saúde.

\section{Colaboradores}

Guimarães JR (0000-0003-0218-3405)* e Santos RT (0000-0002-0125-7700)* são responsáveis pela concepção, elaboração e revisão do manuscrito.

\section{Referências}

1. Hayek FA. O caminho da servidão. 6. ed. São Paulo: Instituto Ludwig von Mises; 2010.

2. Cahill D, Cooper M, Konings M, et al. The SAGE handbook of neoliberalism. New York: Routledge; 2018.

3. Springer S, Birch K, MacLeavy J. The handbook of neoliberalism. New York: Routledge; 2016.

4. Hall S. The Neo-Liberal Revolution. Cultural Studies. 2011; 25(6):705-28

5. Pisarello G. Processos Constituyentes: Caminos para la ruptura democrática. Madrid: Editorial Trotta; 2014.

6. Hayek FA. Law, Legislation and Liberty. The Mirage of Social Justice. London: Routledge \& Kegan Paul; 1976.

7. Mirowski P, Plehwe D, editores. The Road from Mont Pèlerin: The Making of the Neoliberal Thought Collective. Cambridge: Harvard University Press; 2009.

8. Brown, W. Undoing the Demos: Neoliberalism's Stealth Revolution. New York: Zone Books; 2015
*Orcid (Open Researcher and Contributor ID). 
9. Sennett R. A Corrosão do caráter: consequências pessoais do trabalho no novo capitalismo. Rio de Janeiro: Record; 1999.

10. Marshall TH. Cidadania, Classe Social e Status. Rio de Janeiro: Zahar; 1967.

11. Bobbio N. A era dos direitos. Rio de Janeiro: Campus; 1992

12. Campos GWS. Réplica: O SUS, todavia, existe! Ciênc. Saúde Colet. 2018; (6):1721-1722.

13. Paggi L. La teoria general del marxismo en Gramsci. In: Gramsci A. Escritos políticos (1917-1933). México: PyP; 1981. p. 13-84.

14. Escorel S. Reviravolta na saúde: origem e articulação do movimento sanitário. Rio de Janeiro: Fiocruz; 1999.

15. Baptista TWF. Caminhos e Percalços da Política de Saúde no Brasil: vinte anos da reforma sanitária. Ministério da Saúde, Projeto Nordeste II, PNUD; 1997.

16. Gerschman S. A democracia inconclusa: um estudo da Reforma Sanitária brasileira. 2. ed. Rio de Janeiro: Fiocruz; 2004.

17. Doimo AM, Rodrigues MMA. A formulação da nova política de saúde no Brasil em tempos de democratização: entre uma conduta estatista e uma concepção societal da atuação política. Política \& Sociedade. 2003; 2(3):95-116.

18. Fleury S. Reforma sanitária brasileira: dilemas entre o instituinte e o instituído. Ciênc. Saúde Colet. 2009; 14(3):743-752.

19. Dulci MS. PSDB: força e limites da resposta liberal aos desafios do Brasil contemporâneo [tese]. Belo Horizonte: Universidade Federal de Minas Gerais; 2010. 306 p.

20. Guimarães J. O PSDB virou um partido golpista? Revista Carta Maior. 2014. [acesso em 2019 jul 25].
Disponível em: https://www.cartamaior.com.br/?/ Editoria/Politica/O-PSDB-virou-um-partido-golpista-/4/32392.

21. Falleiros I, Lima JCF. Saúde como direito de todos e dever do estado. In: Ponte CF, Falleiros I, organizadores. Na corda bamba de sombrinha: a saúde no fio da história. Rio de Janeiro: Fiocruz; 2010. p. 239-278.

22. Piola SF, Servo LMS, Sá EB, et al. Estruturas de financiamento e gasto do sistema público de saúde. In: Fundação Oswaldo Cruz. A saúde no Brasil em 2030 - prospecção estratégica do sistema de saúde brasileiro: estrutura do financiamento e do gasto setorial. Rio de Janeiro: Fiocruz/Ipea/Ministério da Saúde/ Secretaria de Assuntos Estratégicos da Presidência da República, 2013. p. 19-70. (v. 4).

23. Morais HMN, Albuquerque MSV, Oliveira RS, et al. Organizações Sociais da Saúde: uma expressão fenomênica da privatização da saúde no Brasil. Cad. Saúde Pública [internet]. 2018 [acesso 2019 jun 2]; 35(1):1-13. Disponível em: http://www.scielo.br/scielo.php?script=sci_arttext $\&$ pid $=$ S0102 $-311 X 2018000105017 \& \operatorname{lng}=\mathrm{en}$.

24. Paim JS. Sistema Único de Saúde (SUS) aos 30 anos. Ciênc. Saúde Colet. 2018; 23(6):1723-1728.

25. Russo JA, Carrara SL. Sobre as ciências sociais na Saúde Coletiva - com especial referência à Antropologia. Physis [internet]. 2015 [acesso 2019 jun 2]; 25(2):467-484. Disponível em: http://www.scielo.br/ scielo.php?script=sci_arttext\&pid=S01037331201500 0200467\&lng=en.

26. Araújo CEL. Estado e mercado, continuidade e mudança: a dualidade da política de saúde nos governos FHC e Lula [tese]. Belo Horizonte: Universidade Federal de Minas Gerais; 2017. 333 p.

27. Giovanella L, Mendoza-Ruiz A, Pilar A, et al. Sistema universal de saúde e cobertura universal: desvendando pressupostos e estratégias. Ciênc. Saúde Colet. 2018; 23(6):1763-76. 
28. Braga IF. Empresariado e Políticas Públicas de Saúde no Brasil Contemporâneo. Rio de Janeiro: Fiocruz; 2018.

29. Sestelo JAF. Planos de Saúde e dominância financeira. Salvador: EDUFBA; 2018.

30. Santos RT. Dilemas Públicos e demandas corporativas: a Reforma Sanitária e a ação sindical. In: Fleury S, organizadora. Teoria da Reforma Sanitária: diálogos críticos. Rio de Janeiro: Fiocruz; 2018. p. 221-246. (v. 1).

31. Bahia L. Mudanças e padrões nas relações público-privadas: seguros e planos de saúde no Brasil [tese]. Rio de Janeiro: Fundação Oswaldo Cruz; 1999. 379 p.
32. Polanyi K. A Grande Transformação: as origens políticas e económicas do nosso tempo. 2. ed. São Paulo: Elsevir; 2011.

33. Mbembe A. Crítica da Razão Negra. São Paulo: N-1 edições; 2018.

Recebido em 03/06/2019

Aprovado em 25/08/2019

Conflito de interesses: inexistente

Suporte financeiro: Fundação de Amparo à Pesquisa do Estado de Minas Gerais (Fapemig) 